\title{
REMOTE SENSING OF MESOSPHERIC WINDS WITH THE HIGH-RESOLUTION DOPPLER IMAGER
}

\author{
PAUL B. HAYS and the HRDI SCIENCE TEAM* \\ Department of Atmospheric, Oceanic and Space Sciences. The University of Michigan, \\ Ann Arbor. MI 48109-2143, U.S.A.
}

\begin{abstract}
Observations of the winds in the upper atmosphere obtained with the High-Resolution Doppler Intager (HRDI) un the Upper Almosphere Research Sulellite (UARS) ale discussed. This instrument is a very stable high-resolution triple-etalon Fabry-Perot interferometer, which is used to observe the slight Doppler shifts of absorption and emission lines in the $\mathrm{O}_{2}$ Atmospheric bands induced by atmospheric motions. Preliminary observations indicate that the winds in the mesosphere and lower thermosphere are a mixture of migrating and non-migrating tides, and planetary-scale waves. The mean meridional winds are dominated by the 1,1 diurnal tide which is easily extracted from the daily zonal means of the satellite observations. The daily mean zonal winds are a mixture of the diurnal tide and a zonal flow which is consistent with theoretical expectations.
\end{abstract}

\section{INTRODUCTION}

This paper is the first published discussion of results from the High-Resolution Doppler Imager (HRDI) instrument onboard the Upper Atmosphere Research Satellite (UARS), which was launched on 12 September 1991. The object of this satellite mission is to study the chemical and dynamical processes that determine the state of the upper atmosphere. HRDI is a high-resolution interferometer which is designed to make measurements both for the stratosphere and mesosphere. The results presented here will only consider observations of the dynamic state of the mesosphere.

The following discussion includes a description of the emission features employed for the observations, the instrumental technique and significant results from the first studies of HRDI-measured winds. Several examples of measured altitude profiles of the mesospheric winds are presented and are used to illustrate that the inversion process is self-consistent. These profiles may be summed over a period of several days to provide zonally averaged meridional and zonal winds in the mesosphere for morning. mid-day and afternoon at altitudes from 65 to $105 \mathrm{~km}$. The averaged wind fields are clearly indicative of tidal structures and are in good agreement with the expected mean winds in the mesosphere. We note that the underlying averaged winds and tides are greatly modified by the addition of strong planetary-scale

* V. J. Abreu, M. D. Burrage, D. A. Gell, H. J. Grassl, A. R. Marshall, Y. T. Morton, D. A. Ortland, W. R. Skinner, D. L. Wu and J.-H. Yee. waves, which dominate the observations taken on an individual orbit.

\subsection{Emission from $\mathrm{O}_{2}\left({ }^{1} \Sigma\right)$ and winds}

Among the most brilliant emissions from the Earth's mesosphere are the atmospheric bands of molecular oxygen. These features have been studied since Wallace and Hunten (1968) first described the physical processes by which they are created. Recent investigations by Bucholtz et al. (1986) based on modern rate constants are in agreement with the earlier studies. The results of these studies show that the main $\mathrm{O}_{2}\left({ }^{\prime} \Sigma\right) 0-0$ band at $7620 \AA$ has a brightness of over $2 \times 10^{6} \mathrm{Ra}$ and a strong individual rotational line can have an intensity of greater than $2 \times 10^{5} \mathrm{Ra}$ when viewed on the horizon.

Clearly, these metastable emission lines are of great interest as a means of remotely sensing the state of the Earth's mesosphere. The exact physical processes that produce the emissions from molecular oxygen are not of great consequence when using these lines to determine the winds in the atmosphere. Of importance are the results of Bucholtz et al. (1986) who state that the volume emission rate for the " $A$ " band has a broad maximum of about $10^{5}$ photons $\mathrm{cm}^{-3} \mathrm{~s}^{-1}$ extending from about $40-90 \mathrm{~km}$ with an exponential decrease above $90 \mathrm{~km}$. It should also be noted that, since this emission originates from the ground state of one of the major constituents of the Earth's atmosphere, the lines are often strongly self-absorbed. The spectrum of $\mathrm{O}_{2}\left({ }^{\prime} \Sigma\right)$ lines is detailed in recent simulations published by Abreu et al. (1989). These authors considered the influence of self-absorption on the emitted and scattered light viewed on the Earth's limb, and the study clearly demonstrated that absorp- 
tion plays an important tole in the shape of the spectrum when the tangent point of the observation is below $80 \mathrm{~km}$. In the present investigation, it has been found that wind measurements can be made from about $60 \mathrm{~km}$ upwards using a weak line that is not significantly self-absorbed, changing to stronger lines as higher altitudes are viewed. The results that will be presented here are obtained by employing a detailed model of the self-absorption effect when observing winds using the Doppler technique.

\subsection{The High Resolution Doppler Imager (HRDI)}

The High-Resolution Doppler Imager (HRDI) is the primary instrument for measuring the dynamics of the stratosphere and mesosphere onboard the Upper Atmosphere Research Satellite (UARS). UARS was launched on 12 September 1991 and HRDI has been collecting data since 1 October 1991. The goal of $\mathrm{HRDI}$ is to measure wind velocities in the stratosphere and mesosphere during the day and in the mesosphere and lower thermosphere at night to an accuracy of 5 $\mathrm{m} \mathrm{s}^{-1}$. Winds in the stratosphere are determincd by measuring Doppler shifts of $\mathrm{O}_{2}$ Atmospheric band $\left(b^{1} \Sigma_{q}^{+}-X^{3} \Sigma_{g}^{-}\right)$absorption features. Daytime and nighttime winds in the mesosphere and lower thermosphere are determined by observations of emission lines in the $\mathrm{O}_{2}$ " $A$ " band $\left(b^{1} \Sigma_{g}^{+}-X^{3} \Sigma_{a}^{-}\right)(0-0)$.

A complete description of the HRDI instrument can be found in Hays et al. (1992) and only a brief overview is provided here. HRDI uses three FabryPerot etalons in series to observe emission and absorption lines. The Fabry-Perot interferometer was chosen for this task because of its large light-gathering power and high resolution. The periodic nature of the transfer function of a single-etalon Fabry-Perot interferometer, however, is not well suited for daytime measurements, in which an absorption line is to be viewed in the presence of a continuum. Consequently, the instrument includes three etalons designed to reduce the amount of unwanted light that would otherwise be transmitted through a single etalon. Light from the atmosphere is collected by a fully gimbaled telescope which allows limb scans to be performed at any azimuth. The field of view for atmo-
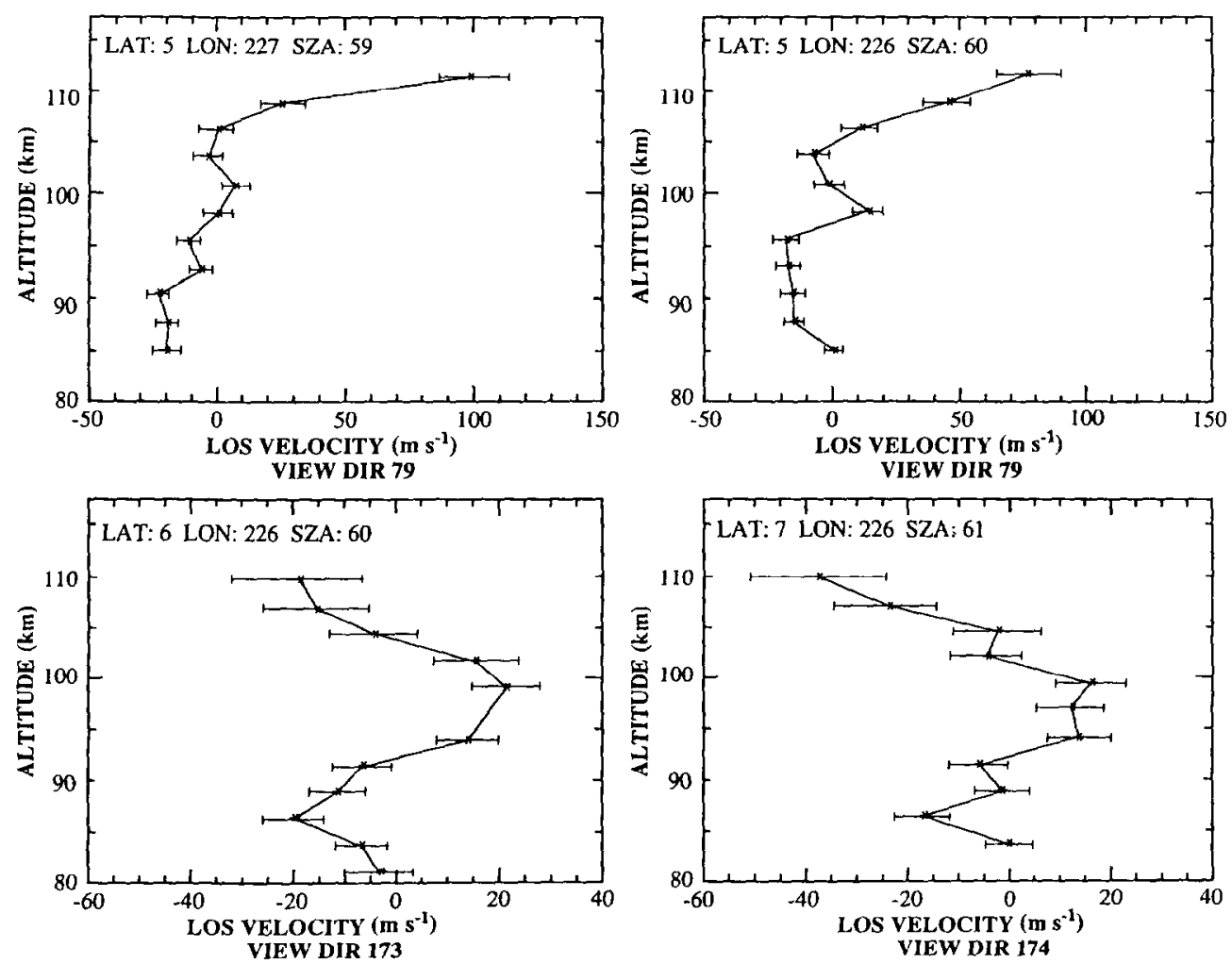

FIG. 1. FOUR LINE-OF-SIGHT WIND PROFILES FROM LIMB SCANS VIEWING THE SAME REGION OF THE ATMOSPHERE. The latitude, longitude and solar zenith angle at the tangent point and the angle between the viewing vector and longitude circle at the tangent point are indicated. 

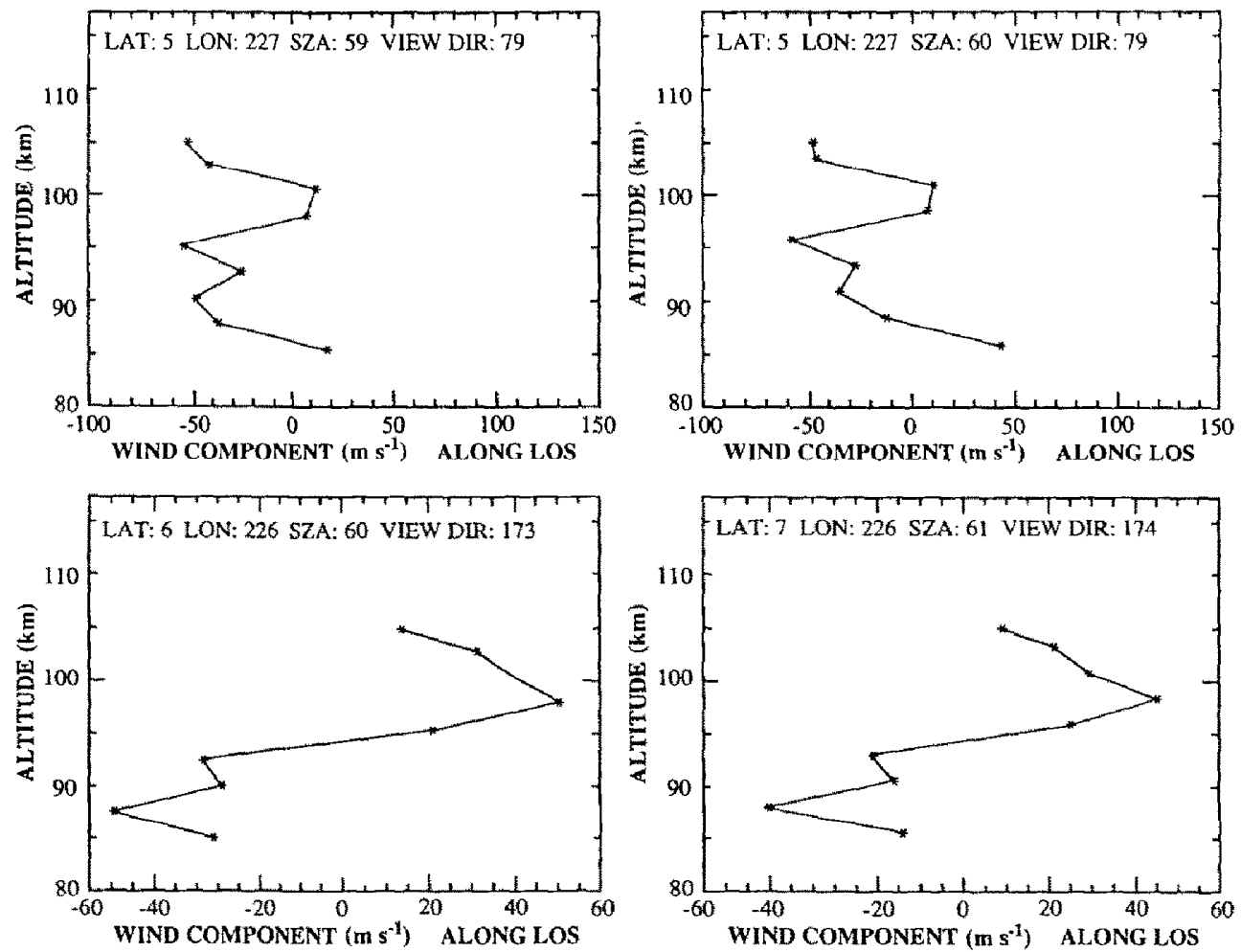

FiG. 2. WIND COMPONENTS ALONG THE LINE OF SIGHT OBTAINED FROM THE INVERSION OF THE PROFILES IN FIG. 1 .

spheric observations is $0.13^{\circ}$ vertically by $1.2^{\circ}$ horizontally. The instrument allows selection of one of 13 spectral regions by inserting $0.8 \mathrm{~nm}$ bandwidth filters into the optical path. A 31 -element spectrum of a $0.50 \mathrm{~cm}^{-1}$ region is measured with a multi-anode concentric-ring detector. This is achieved by means of an anode pattern that mimics the interference pattern produced by the interferometers. Such a device is known as an Image Plane Detector (IPD) (Hays et al., 1981; Killeen et al., 1983 ; Killeen and Hays, 1984 ; Hays and Wang, 199I). The interferometer is tuned to the desired wavelength by using piezoelectric devices to control the spacing of the gap in two of the three etalons. The resolution of the instrument is approximately $0.05 \mathrm{~cm}^{-1}$. This instrument is extremely stable, exhibiting drifts of the passband of less than $4 \times 10^{-5} \mathrm{~cm}^{-1} \mathrm{day}^{-1}$.

\section{OBSERV $A$ TIONS OF WINDS}

The Doppler shift of individual rotational lines of the $\mathrm{O}_{2}$ Atmospheric band is observed by HRDI and used for determining winds. Vector winds are obtained by observing the same atmospheric volume from two nearly orthogonal viewing directions. This is performed by using the pointing capability of the telescope and the spacecraft motion. For example, if the telescope is directed to observe a volume of atmosphere at $45^{\circ}$ to the spacecraft velocity vector, then 9 min later, nearly the same volume can be observed by moving the telescope to $135^{\circ}$ to the spacecraft velocity vector. The apparent Doppler shift as determined by the instrument is a weighted average of the velocity component at each altitude along the line of sight. We refer to this average as the line-ofsight (LOS) velocity. Profiles of this apparent velocity must be mathematically inverted using the known weighting functions to obtain the actual altitude profiles of the wind.

The determination of the LOS velocity is equivalent to determining the location of the spectral line on the detector. The interferometer is sensitive to very small wavelength shifts; for example a $10 \mathrm{~m} \mathrm{~s}^{-1}$ wind corresponds to only a $4 \times 10^{-4} \mathrm{~cm}^{-1}$ shift. In order to determine the LOS wind from the position of the line on the detector, it is necessary to know where the line 


\section{HRDI WINDS AT 90 km, DAY 91311}

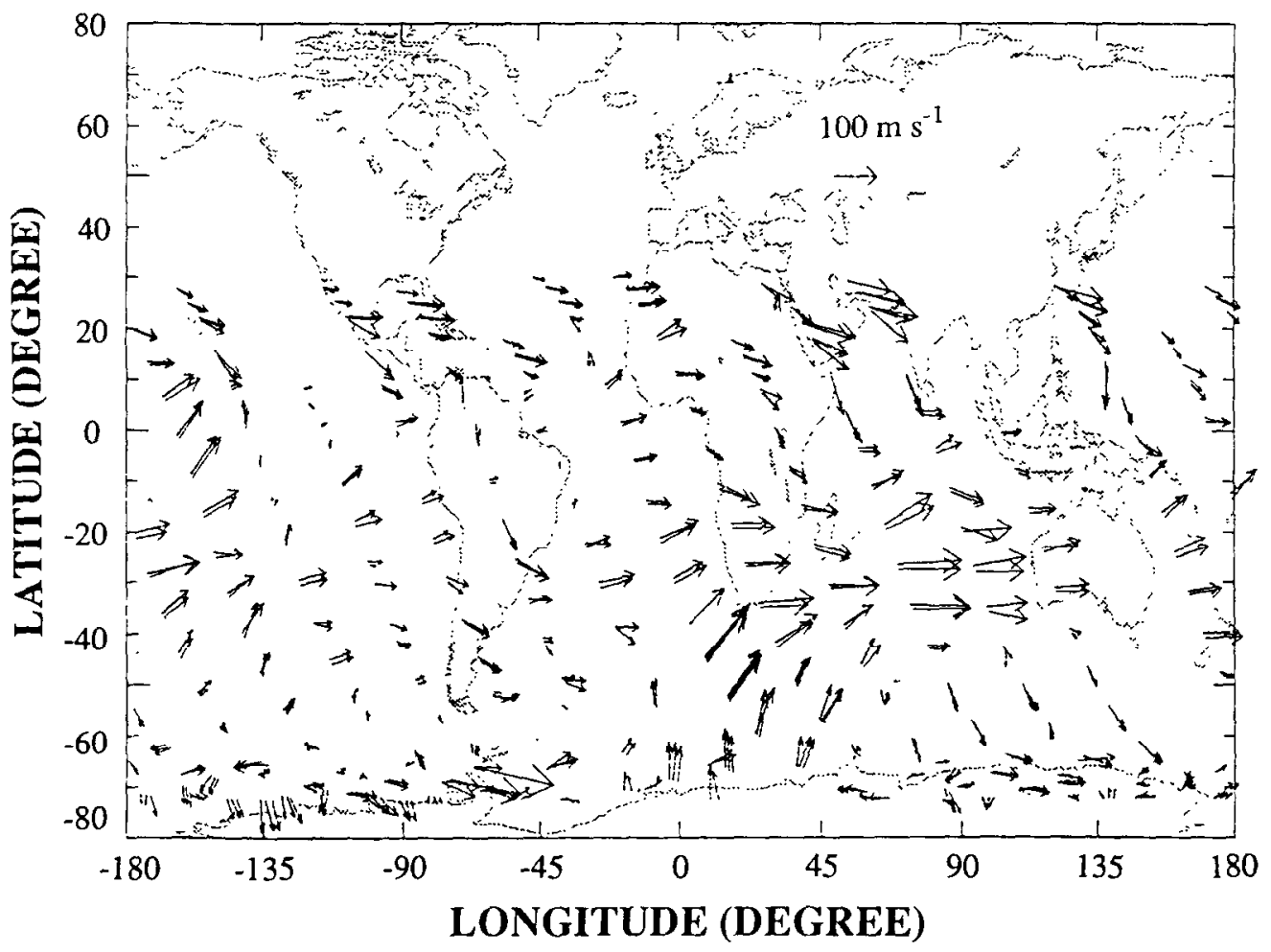

FIG. 3. WINU FIELD OF $90 \mathrm{~km}$ OBTAINED FROM HRDI MEASUREMENTS ON DAY 91311.

would fall in the absence of a Doppler shift. This is difficult to do a priori, since neither the positions of the $\mathrm{O}_{2}$ lines nor the instrument calibration are known with sufficient accuracy. This zero-reference problem is common to all instruments that determine winds from their Doppler shift. The HRDI instrument employs geophysical measurements to estimate the zero position to within about $10 \mathrm{~m} \mathrm{~s}^{-1}$. The technique assumes that global-mean winds do not change rapidly (over a period of a day or two) and that when properly averaged, the global-mean meridional winds will be zero. Improved estimates of the zero-reference positions are being determined by a comparison of HRDI data with correlative measurements.

The self-absorption of $\mathrm{O}_{2}$ Atmospheric lines must be considered in both the data collection and analysis. The brightness and the amount of self-absorption of the line is dependent on the rotational-line quantum number; lower $J$ valued lines typically are stronger and brighter but have more self-absorption. The choice of which line to use depends on altitude. At high altitudes where self-absorption is small, a strong line is selected. As the atmosphere is penetrated more deeply, a balance must be struck between line brightness and self-absorption. A line with a very high rotational quantum number may have no significant selfabsorption, but the brightness may be too small to make it of any value and therefore, in practice, some self-absorption must be tolerated. Detailed studies of these considerations have been performed by Yee et al. (1992).

In order to scan the atmosphere from 65 to $110 \mathrm{~km}$, three different rotational lines of different strengths are used. Data are collected from the same volume of atmosphere twice at each viewing direction (telescope moving up and down). A line of "medium" strength is used at all altitudes during the up scan, while the down scan uses a "strong" line at high altitudes (85$110 \mathrm{~km})$ and a "weak" line at lower altitudes $(65-85$ $\mathrm{km})$. The use of two lines at each altitude allows the temperature and volume emission rate to be measured in addition to the winds. The relative brightness of the lines depends both on the temperature of the atmosphere which determines the rotational distribution and the $\mathrm{O}_{2}$ density profile which, in turn, controls the degree of self-absorption. In this early study, the $\mathrm{O}_{2}$ 
ZONALLY AVERAGED ZONAL WINDS, DAY 92034
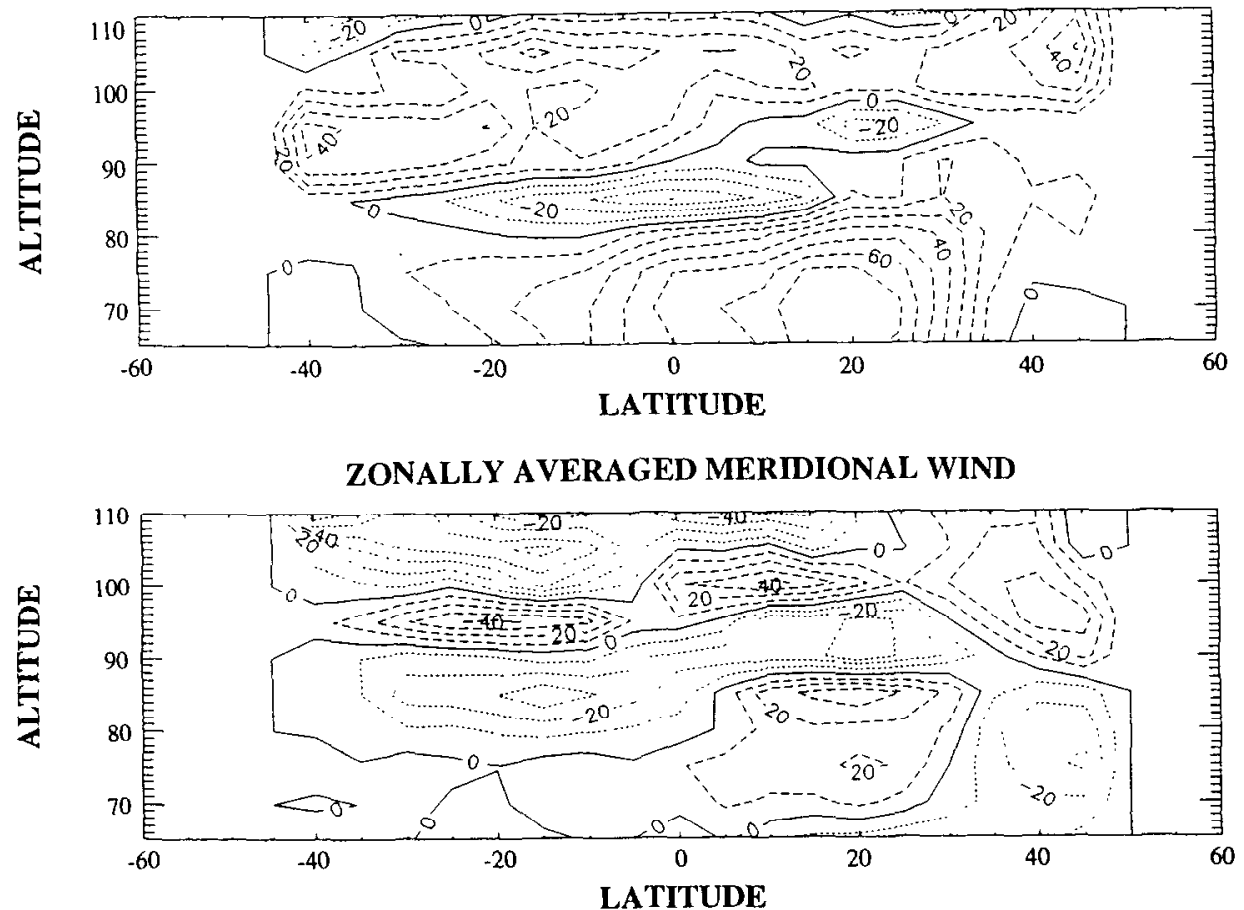

Fig. 4. ZONALly AVERAGEd WIND COMPONENTS FOR 3 FEBRUARY 1992. Contour intervals are in meters per second.

ZONALLY A VERAGED ZONAL WINDS, DAY 92044
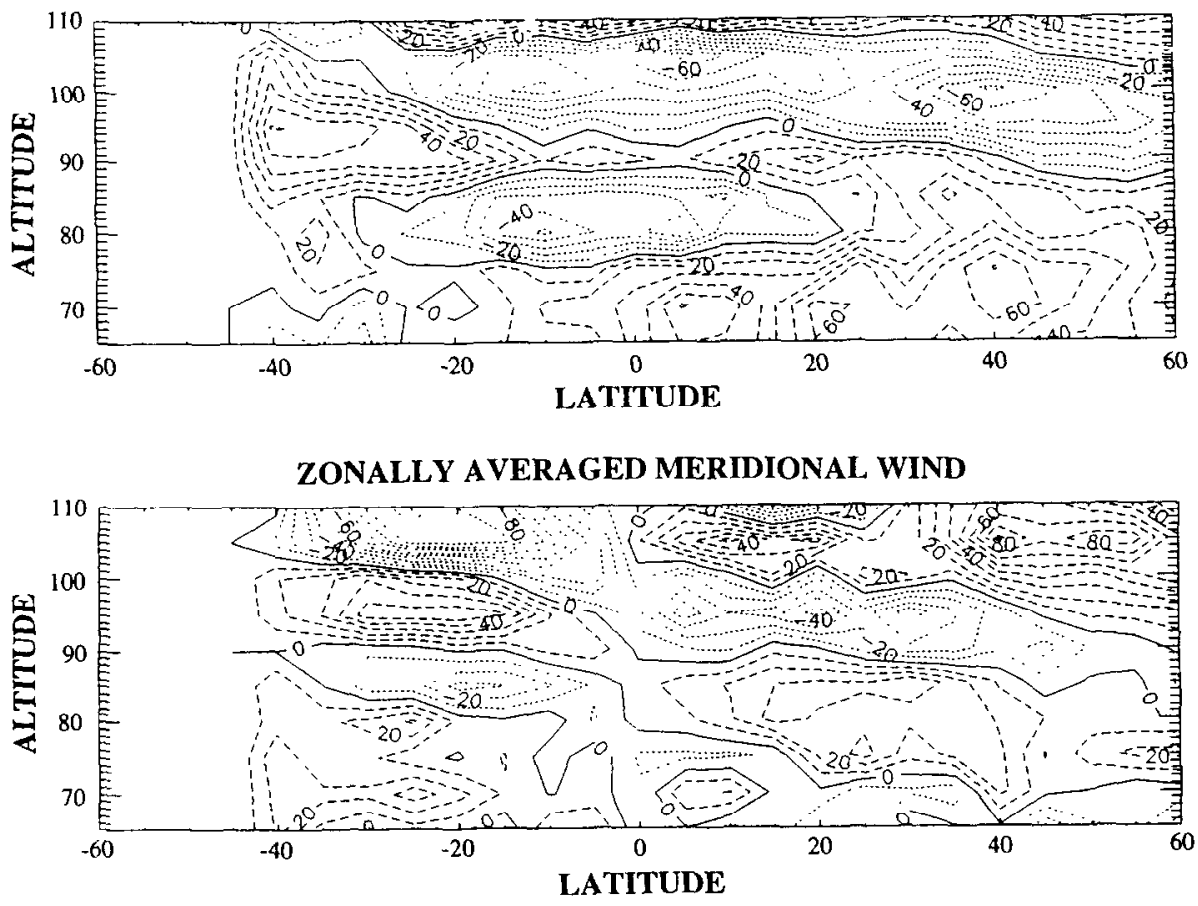

Fig. 5. ZONALly AVERAGEd WIND COMPONENTS FOR 13 February 1992. 

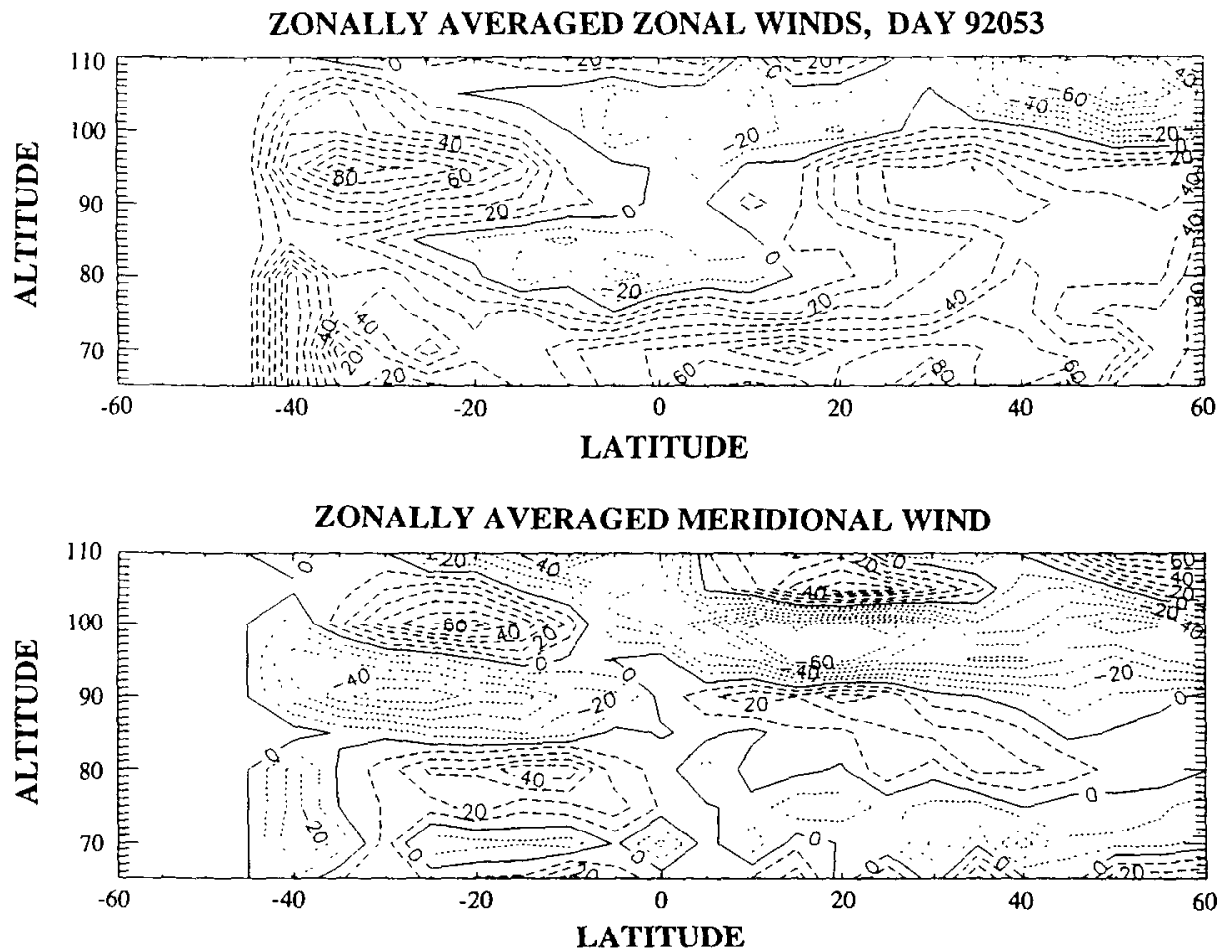

Fig. 6. Zonally aVeraged Wind COMPONENTS For 22 FEBruary 1992.
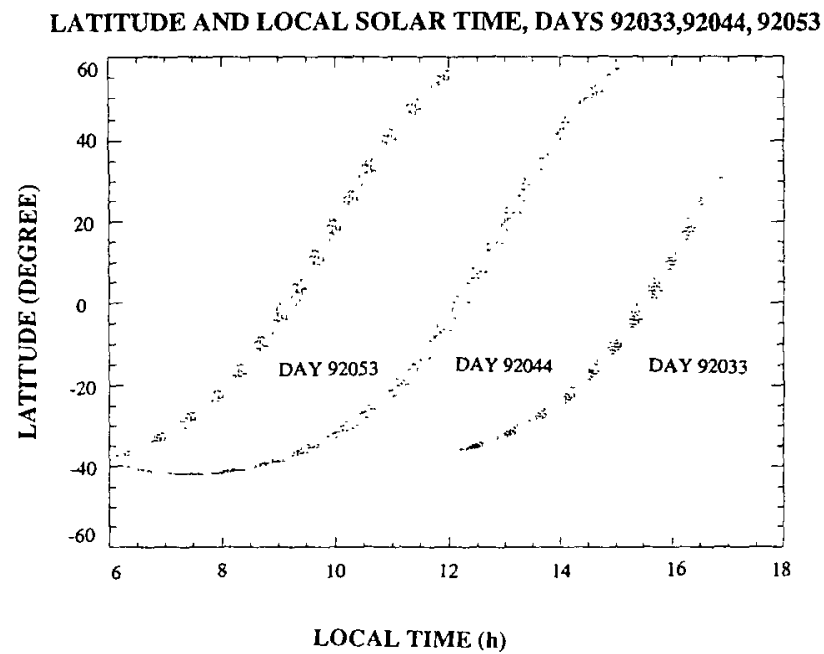

Fig. 7. Plot of local time vs latitude, ILluStrating hOW THE COVERAGE CHANGES FROM DAY TO DAY. 
density profile is not measured, but is instead obtained from models. The temperature is uniquely determined by the ratio of the brightness of the two lines after they have been corrected for self-absorption, and the volume emission rate can be readily calculated once the temperature is known. The derived temperature and volume emission rates are used in the calculations of the weighting functions employed in the wind retrieval. The wind vectors are obtained by using the calculated weighting functions and a sequential estimator (Rodgers, 1976) to invert the line of sight winds.

\section{MESOSPHERIC WINDS}

The previous section described the method used to measure the wind fields in the mesosphere and lower thermosphere. This section will discuss the results of these measurements and consider the implications of the observations.

\subsection{Altitude profiles of winds}

The primary product of the observations from HRDI is the measurement of the line-of-sight component of the wind as a function of altitude. In Fig. 1 we show a series of line-of-sight winds with their associated error bars. In the figure, there are four limb scans of the same region of the atmosphere. Two of these are taken in the forward direction and the other two are taken 9 min later, looking back at the same volume of space. The similarity of the profiles shows that the measurement errors are small and that the atmosphere has a corrclation distance exceeding that between the individual scans. Many observations show evidence of gravity waves which have horizontal wavelengths exceeding the intersample distance of about $120 \mathrm{~km}$.

The wind components along the line of sight obtained from the sequential estimation-inversion technique for the observations in Fig. 1 are presented in Fig. 2. These inverted wind profiles retain the basic character of the primary line-of-sight measurement, but the inverted winds have larger amplitude modulations with altitude and these modulations are shifted slightly upward. This behavior is expected since the line-of-sight winds are a weighted average along the viewing direction and thus appear to have smaller modulations located at lower altitudes. Some very small-scale waves that can be seen in the original observations are removed by the inversion process. The results presented in Fig. 2 are clearly in general accord with previous observations from rockets, meteor trails and radars (Miyahara et al., 1991). The vertical scales of interest are of the order of $20 \mathrm{~km}$ and wind amplitudes show the expected increase with altitude. On an average day, over 2000 altitude profiles of line-of-sight wind are obtained and are converted into altitude profiles of zonal and meridional winds.

\subsection{Global wind fields}

It is difficult to immediately reconcile the pattern of winds observed by HRDI with the conventional view of mesospheric dynamics. A representative sample of the vector wind field obtained at an altitude of $90 \mathrm{~km}$ is shown in Fig. 3, where the vectors are placed at the point at which the various lines of sight are tangent to the surface of the Earth. A single day's observations are obtained in a track that is fixed in local time at various latitudes, while sequential orbits vary in longitudinal coverage. The global wind pattern generated by this technique will not correspond to the conventional synoptic view. Indeed, if the only contributions to the winds were from simple solar-driven tides, there should be no longitudinal variation in the observed pattern. This is clearly not what is observed with HRDI. The observed wind pattern, which is very structured in both longitude and latitude, persists over many days. This suggests that the dynamic fields in the mesosphere consist of a mixture of tides and planetary waves.

Probably the most conventional view of the dynamics of the mesosphere and lower thermosphere is provided by taking zonal averages of the meridional and zonal winds. One-day zonal averages of orbits that cross the equator in the morning, near noon and in the afternoon are presented in Figs 4-6. The orbit tracks for these conditions are shown in Fig. 7. These averaged wind fields show very clearly the expected tidal structures. seen most distinctly in the meridional direction where the mean winds are small. The simple 1,1 diurnal tide is the obvious feature of these averages. A comparison of these results with theoretical studies such as Forbes (1982) is striking.

The meridional winds obtained near noon (Fig. 5) are characterized by vertical wavelengths of about 20 $\mathrm{km}$. The oscillations are centered near the equator and extend to between $40^{\circ}$ and $50^{\circ}$ latitude in both hemispheres. The zonal winds display the same features, but are complicated by the mean zonal winds which are as large as or larger than the tidal structures. However, the same diurnal 1,1 tide is very clear in the zonal wind maps. The summer easterly mean wind and winter westerlies are clearly seen at the lower altitudes. These features are even more distinct when a model of the diurnal tide is used to remove the tidal oscillations from the observations.

\section{CONCLUSION}

The High-Resolution Doppler Imager flown on the Upper Atmosphere Research Satellite has begun to 
provide a new source of valuable information on the dynamics of the mesosphere and lower thermosphere. The observations are in the form of line spectra of individual lines from the Atmospheric " $A$ " band of molecular oxygen. which are shifted with respect to their rest position if the atmosphere is in motion. Doppler shifts have been obtained over the dayside of the Earth and, when inverted, yield profiles of the meridional and zonal winds. The results obtained from HRDI thus far challenge existing models when viewed from a global perspective. However, daily and several-day averages of the zonal- and meridionalmean winds are in agreement with the predicted tidal and mean-wind features. The simple 1,1 tide is very much in evidence, as are the predicted zonal-mean winds at low altitudes.

A major new result of these preliminary observations is the strong longitudinal structure in the wind fields. The Iarge-scale, wave-like features which are observed often persist over several days, as expected of planetary-scale waves. The smaller features, which may be large-scale gravity waves, are shorter lived than the large structures and have yet to be related to their sources.

The results presented here represent a very limited sample of those being analyzed by the UARS science team. We expect that diurnal and seasonal variations will emerge from these data as a larger body of information is examined. There is also early evidence for magnetic storm effects that will be investigated further. The initial results from HRDI are extremely interesting and will have a profound influence on our understanding of the dynamics of the mesosphere and lower thermosphere.

Acknowledgments - This paper is dedicated to Sir David Bates who started one of us (Paul B. Hays) on the path of study that led to the creation of the High-Resolution Doppler Imager. David Bates gave me a unique gift when I studied with him at Queen's University, the gift of wonder about the physical world and a desire to understand that world. Only a rare and gifted teacher can give such a unique gift and I will always be grateful for the chance to see the world as he sees it.

We also wish to express our thanks to the $U A R S$ science and engineering teams who have worked so closely with the HRDI science team to make the UARS mission and the HRDI investigation a success. This work is sponsored by NASA through Contract No. NAS 5-27751.

\section{REFERENCES}

Abreu, V. J., Bucholtz, A.. Hays, P. B., Ortland. D., Skinner, W. R. and Yee, J.-H. (1989) Absorption and emission line shapes in the $\mathrm{O}_{2}$ atmospheric bands: theoretical model and limb viewing simulations. Appl. Optics 28, 2128.

Bucholtz, A.. Skinner, W. R., Abreu, V. J. and Hays, P. B. (1986) The dayglow of the $\mathrm{O}_{2}$ Atmospheric band system. Planet. Space Sci. 34, 1031.

Forbes, J. M. (1982) Atmospheric tides, 1. Model description and results for the solar diurnal component. J. geophys. Res. 87, 5222 .

Hays, P. B., Abreu, V. J., Dobbs, M. E., Gell, D. A., Grassl, H. J. and Skinner, W. R. (1992) The High Resolution Doppler Imager on the Upper Atmosphere Research Satellite. J.geophys. Res. (submitted).

Hays, P. B., Killeen, T. L. and Kennedy, B. C. (1981) The Fabry-Perot interferometer on Dynamics Explorer. Space Sci. Instrum. 5, 395.

Hays, P. B. and Wang, J. (1991) Image plane detector for Fabry-Perot interferometers : physical model and improvement with anticoincidence detection. Appl. Opt. 30, 3100.

Killeen, T. L. and Hays, P. B. (1984) Doppler line profile analysis for a multichannel Fabry-Perot interferometer. Appl. Opt. 23, 612 .

Killeen, T. L., Kennedy, B. C., Hays, P. B., Symanow, D. A. and Ceckowski, D. H. (1983) Image plane detector for the Dynamics Explorer Fabry-Perot interferometer. Appl. Opt. 22, 3503.

Miyahara, S., Portnyagin, Y. I. and Forbes, J. M. (1991) Mean zonal acceleration and heating of the 70 to $100 \mathrm{~km}$ region. J. geophys. Res. 96, 1225.

Rodgers, C. D. (1976) Retrieval of atmospheric temperature and composition from remote measurements of thermal radiation. Rev. Geophys. Space Phys. 14, 609.

Wallace, L. and Hunten, D. M. (1968) Dayglow of the oxygen $A$ band. J. geophys. Res. 73, 4813.

Yee, J.-H., Hays, P. B., Skinner, W. R., Abreu, V. J. and Ortland, D. A. (1992) Remote sensing of mesospheric wind, temperature, and $\mathrm{O}_{2}\left({ }^{1} \Sigma\right)$ band volume emission rate with the High Resolution Doppler Imager (in preparation). 